(1)

CrossMark

\title{
Palliative care for people with COPD: effective but underused
}

\author{
David M.G. Halpin \\ Affiliation: Dept of Respiratory Medicine, Royal Devon and Exeter Hospital, Exeter, UK.
}

Correspondence: David M.G. Halpin, Dept of Respiratory Medicine, Royal Devon and Exeter Hospital, Barrack Road, Exeter, EX2 5DW, UK. E-mail: d.halpinanhs.net

@ERSpublications

Despite its effectiveness palliative care is underused in the majority of patients with COPD http://ow.ly/d0YH30hPKeu

Cite this article as: Halpin DMG. Palliative care for people with COPD: effective but underused. Eur Respir J 2018; 51: 1702645 [https://doi.org/10.1183/13993003.02645-2017].

Nearly 100000 men and over 65000 women die from chronic obstructive pulmonary disease (COPD) in Europe each year [1]; more die from one of its comorbidities but face the challenges of living and dying with severe COPD during their last years and months. Globally, COPD is the third most common cause of death worldwide and the Global Burden of Disease project estimated that, in 2015, COPD caused 3.2 million deaths, an increase of $11.6 \%$ compared with 1990 [2].

For the people that die of, or with, COPD, their final months are often characterised by a progressive decline in health status, increasing symptoms and increased reliance on family and carers to perform simply daily activities such as washing and dressing. Despite this burden of disease, the vast majority of patients with advanced COPD are not offered palliative care, an approach that centres on the management of symptoms, maintaining quality of life and good communication. The underuse of palliative care was first reported nearly 20 years ago [3] and, since then, national and international guidelines have tried to encourage its adoption. The importance and benefits of palliative care were emphasised in the National Institute for Health and Care Excellence (NICE) COPD guideline in the UK published in 2004 [4] and in the American Thoracic Society/European Respiratory Society position paper published the same year [5]. In the UK, the Department of Health also introduced an "End of Life Care Strategy" in 2008 which was a comprehensive framework aimed at promoting high quality care across the country for all adults approaching the end of life [6]. Against this background, it is particularly disappointing that the study by BLOOM et al. [7], published in this issue of the European Respiratory Journal, shows that between 2004 and 2015 only one in five people dying from COPD in the UK were recorded as having received any palliative care. Just under half of those that did get palliative care only received it during the last 6 months of their life and one third only in their last month of life. There was a progressive increase in the use of palliative care over the decade, indicating that awareness and use of palliative care in COPD is changing, but it is clear that palliative care is still much more likely to be used in people with cancer as in the study people with COPD and lung cancer were $40 \%$ more likely to be offered palliative care than those with COPD alone. A strength of the study is the large number of patients included from the Clinical Practice Research Datalink which covers 674 UK primary care practices, with representative demographics; however, the analysis does depend on practitioners having specifically documented the use of palliative care using one of a number of codes in the electronic patient record. The authors note that practices are financially incentivised to record palliative care approaches, and suggest that this means under-recording, rather than

Received: Dec 192017 | Accepted after revision: Jan 032018

Conflict of interest: None declared.

Copyright OERS 2018 
underuse, is unlikely. In practice the clinicians may have used palliative care approaches for their patients but regarded these as part of standard care and not coded them separately, but even if this is the case, the extent of under-recording is likely to be small and the study still confirms that most people dying of COPD do not receive palliative care.

Palliative care has much to offer for people living with advanced COPD and includes more than just terminal care. It involves close attention to the emotional, spiritual and practical needs and goals of patients and of the people who are close to them, including determining their views on future care through advance directives [8]. Palliative care is not only relevant for people with advanced COPD, it is important for people with other non-malignant respiratory diseases including interstitial lung disease and bronchiectasis $[9,10]$. Both palliative care and rehabilitation have the same aims, and some regard rehabilitation as a palliative approach, but most would see rehabilitation as a powerful component of active restorative care, with palliative care focusing on improving symptoms and quality of life when active approaches are not succeeding.

Even when receiving optimal medical therapy many patients with COPD continue to experience distressing breathlessness and fatigue and often suffer from insomnia, panic, anxiety and depression. Palliative approaches to these symptoms are effective [11] and their use should not be restricted to end of life situations. It is entirely logical to introduce palliative care alongside therapies aimed at correcting the underlying pathophysiological abnormalities and reducing the risk of exacerbations.

Opiates and fans blowing air onto the face can relieve breathlessness [12], oxygen may offer some benefit even if the patient is not hypoxaemic (peripheral capillary oxygen saturation >92\%) [13] and a multidisciplinary integrated palliative and respiratory care approach to breathlessness can be of value [14]. Anxiety and depression can be reduced by pharmacotherapy [4] as well as cognitive behavioural therapy and mind-body interventions (e.g. mindfulness-based therapy, yoga and relaxation) [15]. Mind-body interventions can also improve physical outcomes such as breathlessness and fatigue.

While the ability to use palliative approaches should be part of the skill set of all clinicians managing people with COPD [16], some patients will benefit from referral to specialist palliative care teams, whose multidisciplinary approach can improve a patient's quality of life [17]. Referral needs to be discussed sensitively with patients, with an emphasis on the positive aspects of specialist palliative care input, such as help with symptom control, and family support. There is evidence of the underuse of specialist palliative care services, and referral is sometimes linked more to life expectancy than to the patient's symptom needs. For example, in Belgium, patients with COPD were less likely to be referred to palliative care services than those with other chronic diseases such as heart failure, and patients with COPD who were not referred were more likely to receive inappropriate treatment with a curative or life-prolonging goal rather than a palliative or comfort goal than patients with other conditions who were not referred [18].

Palliative care also involves honest discussion of prognosis and issues such as advance directives about the patient's wishes regarding admission to hospital, ventilation and resuscitation in the event of cardiorespiratory arrest. Surprisingly, many patients do not understand that in most cases COPD is a progressive life limiting condition [19]. Patients who are aware of the prognosis often have concerns regarding the manner of their death with an overriding fear of dying of breathlessness or suffocation, yet they rarely discus these fears with clinicians [19], and clinicians are poor at eliciting patient's concerns [20]. Sometimes patients and their families have unrealistic views on the prognosis and the likely effectiveness of interventions such as ventilation, but these views must be respected. There is also evidence of cultural differences in acceptance of advance directives, both between cultural groups within countries and between countries themselves, but overall their use is increasing [9].

Concerns have been expressed that patients may change their minds about not wanting life-prolonging therapies when they became necessary; however, when this has been studied, in general there appears to be consistency between end of life decisions and preferences stated in advanced directives [21], but of course patients are free to change their mind about accepting or rejecting treatment if they wish. There is evidence that advance care planning improves end of life care and patient and family satisfaction and reduces stress, anxiety and depression in surviving relatives [22], as well as reducing the costs of care [23]. It is important that the details of advance directives are regularly reviewed with patients to ensure that their instructions reflect their current wishes.

Although often uncomfortable for clinicians, open communication regarding death is important to alleviate patients' fears and to allow them to make decisions regarding the management of their care at the end of life. Patients with COPD find it particularly difficult to make decisions in advance about ceilings of care [24] and even when they have had prior experience of interventions such as noninvasive ventilation 
they trust their doctor to make the right decision about its use in future in preference to making their own decision [25]. Nevertheless it is important that they are given the opportunity to discuss such issues.

Patients with COPD appreciate continuity of care and reassurance provided by their primary healthcare team [26, 27] and general practitioners acknowledge that they are in a key position to deliver and coordinate palliative and end of life care for patients with COPD; however, most find it hard to initiate these discussions, partly because of perceived time constraints but also because they have difficulty identifying when they are appropriate, given the difficulty in predicting prognosis in COPD compared to cancer $[28,29]$. Clinicians often feel uncomfortable raising end of life issues and deliberately avoid doing so. There are, however, practical strategies that can be used to facilitate these discussions: raising the implications of the diagnosis; using uncertainty to ease discussion; building relationship with patients; being caring and respectful; beginning discussion early in disease course; identifying and using opportunities such as an exacerbation or hospitalisation to discuss prognosis; and working as a team. Patients with advanced disease are often receptive to the dual agenda: "Hope for and expect the best, and prepare for the worst" [30].

The progressive decline in activities of daily life and social isolation for patients with end-stage COPD are reflected by changes in the roles and responsibilities of spouses and families. They frequently take on multiple new roles as the illness progresses, including nursing the patient and taking over all household tasks $[26,31]$. This can put a considerable strain on them and they also need the psychosocial support that palliative care offers, as well as bereavement counselling after the patient's death [32].

The Global Strategy for the Diagnosis, Management, and Prevention of Chronic Obstructive Lung Disease (GOLD) report now recommends "that all clinicians managing patients with COPD should be aware of the effectiveness of palliative approaches to symptom control and use them in their practice" [12]. Although palliative care is about more than just end of life care, clinicians managing patients with advanced respiratory disease would do well to reflect on the words of Dame Cicely Saunders, founder of the modern hospice movement in the UK: "How people die remains in the memory of those who live on" [33].

\section{References}

1 Eurostat. Causes of death in the EU in 2012. Brussels, European Commission, 2015. http://ec.europa.eu/eurostat/ en/web/products-press-releases/-/3-10092015-AP

2 Global, regional, and national deaths, prevalence, disability-adjusted life years, and years lived with disability for chronic obstructive pulmonary disease and asthma, 1990-2015: a systematic analysis for the Global Burden of Disease Study 2015. Lancet Respir Med 2017; 5: 691-706.

3 Gore JM, Brophy CJ, Greenstone MA. How well do we care for patients with end stage chronic obstructive pulmonary disease (COPD)? A comparison of palliative care and quality of life in COPD and lung cancer. Thorax 2000; 55: 1000-1006.

4 National Institute for Clinical Excellence (NICE). Chronic obstructive pulmonary disease. National clinical guideline for management of chronic obstructive pulmonary disease in adults in primary and secondary care. Thorax 2004; 59: Suppl. 1, 1-232.

5 Celli BR, MacNee W. Standards for the diagnosis and treatment of patients with COPD: a summary of the ATS/ ERS position paper. Eur Respir J 2004; 23: 932-946.

6 Department of Health. End of Life Care Strategy. London, Department of Health, 2008.

7 Bloom CI, Slaich B, Morales DR, et al. Low uptake of palliative care for COPD patients within primary care in the UK. Eur Respir J 2018; 51: 1701879.

8 Morrison RS, Meier DE. Clinical practice. Palliative care. N Engl J Med 2004; 350: 2582-2590.

9 Halpin DMG, Seamark DA, Seamark CJ. Palliative and end-of-life care for patients with respiratory disease. In: Bellia V, Antonelli Incalzi R, eds. Respiratory Diseases in the Elderly (ERS Monograph). Sheffield, European Respiratory Society, 2009; pp. 327-353.

10 Kreuter M, Bendstrup E, Russell AM, et al. Palliative care in interstitial lung disease: living well. Lancet Respir Med 2017; 5: 968-980.

11 Seamark DA, Seamark CJ, Halpin DM. Palliative care in chronic obstructive pulmonary disease: a review for clinicians. J R Soc Med 2007; 100: 225-233.

12 Vogelmeier CF, Criner GJ, Martinez FJ, et al. Global Strategy for the Diagnosis, Management, and Prevention of Chronic Obstructive Lung Disease 2017 Report: GOLD Executive Summary. Eur Respir J 2017; 49: 1700214.

13 Uronis HE, Ekstrom MP, Currow DC, et al. Oxygen for relief of dyspnoea in people with chronic obstructive pulmonary disease who would not qualify for home oxygen: a systematic review and meta-analysis. Thorax 2015; 70: 492-494.

14 Higginson IJ, Bausewein C, Reilly CC, et al. An integrated palliative and respiratory care service for patients with advanced disease and refractory breathlessness: a randomised controlled trial. Lancet Respir Med 2014; 2: 979-987.

15 Farver-Vestergaard I, Jacobsen D, Zachariae R. Efficacy of psychosocial interventions on psychological and physical health outcomes in chronic obstructive pulmonary disease: a systematic review and meta-analysis. Psychother Psychosom 2015; 84: 37-50.

16 Quill TE, Abernethy AP. Generalist plus specialist palliative care - creating a more sustainable model. N Engl J Med 2013; 368: 1173-1175.

17 Gaertner J, Siemens W, Meerpohl JJ, et al. Effect of specialist palliative care services on quality of life in adults with advanced incurable illness in hospital, hospice, or community settings: systematic review and meta-analysis. BMJ 2017; 357: j2925. 
18 Beernaert K, Cohen J, Deliens L, et al. Referral to palliative care in COPD and other chronic diseases: A population-based study. Respir Med 2013; 107: 1731-1739.

19 Gardiner C, Gott M, Small N, et al. Living with advanced chronic obstructive pulmonary disease: patients concerns regarding death and dying. Palliat Med 2009; 23: 691-697.

20 Tulsky JA. Interventions to enhance communication among patients, providers, and families. J Palliat Med 2005; 8: Suppl. 1, S95-S102.

21 Hammes BJ, Rooney BL. Death and end-of-life planning in one midwestern community. Arch Intern Med 1998; 158: 383-390.

22 Detering KM, Hancock AD, Reade MC, et al. The impact of advance care planning on end of life care in elderly patients: randomised controlled trial. BMJ 2010; 340: c1345.

23 Klingler C, in der Schmitten J, Marckmann G. Does facilitated advance care planning reduce the costs of care near the end of life? Systematic review and ethical considerations. Palliat Med 2016; 30: 423-433.

24 MacPherson A, Walshe C, O'Donnell V, et al. The views of patients with severe chronic obstructive pulmonary disease on advance care planning: a qualitative study. Palliat Med 2013; 27: 265-272.

25 Beckert L, Wiseman R, Pitama S, et al. What can we learn from patients to improve their non-invasive ventilation experience? 'It was unpleasant; if I was offered it again, I would do what I was told'. BMJ Support Palliat Care 2016; in press [https://doi.org/10.1136/bmjspcare-2016-001151].

26 Seamark DA, Blake SD, Seamark CJ, et al. Living with severe chronic obstructive pulmonary disease (COPD): perceptions of patients and their carers. An interpretative phenomenological analysis. Palliat Med 2004; 18 : 619-625.

27 Exley C, Field D, Jones L, et al. Palliative care in the community for cancer and end-stage cardiorespiratory disease: the views of patients, lay-carers and health care professionals. Palliat Med 2005; 19: 76-83.

28 Elkington H, White P, Higgs R, et al. GPs' views of discussions of prognosis in severe COPD. Fam Pract 2001; 18: 440-444.

29 Gott M, Gardiner C, Small N, et al. Barriers to advance care planning in chronic obstructive pulmonary disease. Palliat Med 2009; 23: 642-648.

30 Hansen-Flaschen J. Chronic obstructive pulmonary disease: the last year of life. Respir Care 2004; 49: 90-98.

31 Bergs D. "The Hidden Client" - women caring for husbands with COPD: their experience of quality of life. J Clin Nurs 2002; 11: 613-621.

32 Hasson F, Spence A, Waldron M, et al. Experiences and needs of bereaved carers during palliative and end-of-life care for people with chronic obstructive pulmonary disease. J Palliat Care 2009; 25: 157-163.

33 Saunders C. Pain and impending death. In: Wall PD, Melzak R, eds. Textbook of Pain. 2nd Edn. Edinburgh, Churchill Livingstone, 1989; pp. 624-631. 